\title{
Polysyndactyly-cardiac malformation syndrome
}

INSERM

\section{Source}

INSERM. (1999). Orphanet: an online rare disease and orphan drug data base.

Polysyndactyly-cardiac malformation syndrome. ORPHA:2934

Polysyndactyly-cardiac malformation syndrome is characterized by polysyndactyly, hexadactyly (duplication of the first toe) and complex cardiac malformation (including atrial and ventricular septal defect, single ventricle, aortic dextroposition, or dilation of the right heart). It has been described in six patients from three unrelated families. Other manifestations were present in some patients (i.e. facial dysmorphism, hepatic cysts). 